\title{
Analysis of the Function of Music Hearing in Piano Playing
}

\author{
Yiyu Zhu \\ University of Sanya, Sanya, Hainan, 572022
}

\author{
Keywords: Piano Playing, Music Hearing, Function Analysis
}

\begin{abstract}
Music is a kind of auditory art, all the music activities are related to "listening", piano playing is no exception. From the piano's own characteristics, you need a complete listening ability to fully understand the piano, master the piano; from the piano requirements point of view, need to have a good ability to hear the audition to play better works. This shows that music listening plays an important role in piano playing, and the use of music in piano playing is critical.
\end{abstract}

\section{Introduction}

Since the piano has been introduced into China since the development of piano education has made a lot of gratifying achievements, but this does not mean that our piano education has been perfect, there is still a more common phenomenon: people too much emphasis on technology, Skill, while ignoring the more important point - music hearing. 1, students begin school piano, on the one hand the teacher itself is not enough attention to the music, not to guide students to use music to practice music; the other hand, even if the teacher told the importance of student music and hearing, But students in the practice process, too much emphasis on waving, knowledge music, and forget the existence of music and hearing. 2, the students after a period of learning, gradually realized that technical practice is very important, so too much emphasis on technology, skills, practice, ignoring the music and hearing, did not develop the habit of practicing music with music. 3 , from the beginning of the school to the university (high school) learning, because there is no awareness of the existence and importance of music and hearing, the music hearing the problem has been forgotten, resulting in many students pop up the work though very skilled, but gives the impression Very boring, dull, melody is not smooth, clear, no strength, the level of change, as if a typist in the same work, neither to attract the audience can not move themselves, it is regrettable.

\section{Music Listening in the Piano Practice in the Specific Application}

When we browse the music, attention first focused on the visual, while the application of music and hearing. In the eyes of the music at the same time, the heart will be able to clearly hear the melody of music, and can rely on the experience of listening to help the eyes faster and more accurate view. When the piano sounds, through the external hearing quickly determine whether the play is accurate, so that timely correction. It is strange that they often can not find this error, the main reason is that no attention to "listen", will be wrong on the wrong - no music to hear the sound. So there is a wrong tone, not only to re-read spectrum, but also the correct and wrong sound effects contrast to listen carefully, to develop the habit of using music to distinguish between music and ears. In order to achieve a more realistic playing effect, it is necessary to focus on the music auditory, hear that part of the loopholes in order to adjust the playing mode. Experienced musicians make it easy to read the spectrum quickly and smoothly, mainly because they are ahead of the work they are playing, when they see the music, the corresponding music at the same time appear in their minds, they from the heart Has heard the whole music. In the process of reading music, if the player is not good at or can not through their own "eyes" and internal hearing to constantly "reconnaissance", then his performance will appear too formal, no thought, but the fingers in the Monotonous running. If we can follow the "I see - I hear - I play" this process, the full use of music 
to hear the music of the internal hearing and external hearing very good combination, then our knowledge will be much more accurate.

Sound is the color of the sound, by the sound of the material factors and its overtone and decided. In the nature of the birds singing and lion roar of the same pitch sound is not the same, the material used by the instrument is not the same as the sound, and the same instrument with different methods of playing, will produce a different sound. So different styles of work on the tone requirements are different. Almost all the pianists are very concerned about this, the famous composer, pianist Rachmaninov pointed out that he played the most important and the first consideration is the sound of the issued, and the skills and other issues on the times To the position. The sound of the piano is not just the pupil's imagination, only the light or the weight, the piano's voice can also be gentle or cold, soft or sharp, bright or dark, bright or dark, etc. Wait. The nature of the piano is actually "percussion", it is simple to say that the principle is: touch - through the mechanical transmission of sticky hammer hit the string and pronunciation. This shows that the piano infinite rich sound changes are actually only produced in the keystroke moment touch the way the subtle changes in the way, with the ear to identify which sound is "comfortable" "rounded", before the first to have The correct sound concept, then what is the good voice to meet the requirements? In general, it is like an indispensable voice that people like to communicate and communicate with all the sounds that are needed or sad or joyful or cold or gentle.

Perceived music through the brain to be maintained, when needed to emerge, this is the back spectrum. Backtracking is an important part of piano practice. Backtrack is the same as the back of poetry, the back of the poetic art image, the poet's thoughts and feelings; back spectrum is not a simple note, but the music and ideological and emotional. In accordance with the memory of different ways, can be summarized as five categories: the sound of the memory, the location of the memory, the memory of the action, spectrum memory, analysis of memory. The following focus on the use of audio memory to back spectrum, that is, with music and music to back spectrum. Sound memory: listen to the sound with the ears, you can put the music of the fabric and it produced the effect of combining. Thinking about music, can help your hand with the right to play the action. Different harmony, tone, texture produced by the auditory effect, is an important way to strengthen the memory. Most pianists are able to hear their music from the inside without playing the piano, which is also a way to enhance memory through sound. You can practice with this method, starting from a short song, analyzing the song's body style and style. Put the music in front of you, playing a few times accurately. And then try to draw the music in the brain music song of the process, trying to listen to the song in the heart. If you have been able to remember some of these parts, first to repeatedly recall those forgotten parts, in order to get a complete memory again. And then back to the piano to play this song. If you still do not remember some of the places, look at the score to play these parts several times as much as possible, and then play the song from beginning to end as a test to see if the blurred places this time whether the bomb Get better.

\section{Music Listening in Piano Performance in the Specific Application}

Style, refers to the composer in the creation of the artistic characteristics and creative personality, it depends on the composer's era and cultural background, as well as the composer's ideological tendency, life experience, artistic quality, personality temperament and other subjective factors, Is the contemporaries of the same understanding and evaluation of the product. Grasp the style of the work, is at a higher level on the composer's creative personality and the artistic characteristics of the overall grasp and reproduction. Any piano works, if you can not make their style to make accurate judgments, there is no deep understanding of the works. Whether the player really understands the music works can only be judged by the correct expression of the musical style in his practice. Therefore, only in-depth study of the author's creative techniques, and contact the works of the times, social habits, the author's experience, etc. is possible in the actual performance of the correct grasp of the style of the work in order to better explain the music works.

Whether playing in the daily or on stage, the fundamental purpose of piano playing is to reveal the content of music, characterize a specific mood, rendering the basic emotions, and all this only 
by resorting to the human hearing organs of the music itself can be achieved. Before playing, if we can use our music to listen to the tracks in the mind in the mind "over" again, it will help us to ease the tension. In the performance, the handball is very important, but the music to play a more decisive role, especially on the stage, any situation may occur in an instant, only "thinking in the past," each phrase, every action must prepare in order to be out of or out of the accident. In the process of playing, the ear should always remain keen to listen to their own performance, to adjust the relationship between the keyboard at any time, at any time to identify their own touch, listen to their actual playing sound effects. In the process of playing, to maintain the enthusiasm of music audition, not only can effectively ensure that play in accordance with their intended effect, but also help the spirit of concentration, eliminate distractions, focus on the performance. Of course, this can not be done overnight, more of the need to practice in the practice of accumulation can be done.

In order to make every part of the music accurate and performance of the right, we must respect the original, respect the author on the basis of fully understand and feel the work. But can not blindly imitate, we have to play their own style, their own characteristics, to be innovative. But to do this, can not do without music listening. For example, we would like to know Beethoven's playing style, in addition to his work to play a good, but also to listen to his symphony, a comprehensive understanding of his style. In the absorption of the characteristics of Beethoven and then combined with their own characteristics will be deduced their own piano art. Everything is linked to the piano is also true, it is intertwined with the various disciplines. Only the theoretical knowledge, through the harmony of the song, polyphony, aesthetics and Chinese and foreign music history and other theoretical study, the player's music cultivation and understanding ability will be greatly improved, but this is not enough. To listen more, learn from the public long. Accumulate a variety of audio, improve the ability of music and hearing, enhance the feelings of music and awareness, so as to strengthen the sense of music and the ability to identify the sound. This has a subtle effect on cultivating the music thinking ability of the player and analyzing the ability of the work, and has the effect of promoting the playing level of the piano.

Piano works in a rich musical elements: melody, rhythm, harmony, speed, intensity, style, fabric in order to perceive the music in the above-mentioned various combinations of sound factors and changes, only by the ears are likely to enter the Works of art, artistic conception, imagination, association and understanding, shows how important music is heard. Music to listen to the art of hearing, only by hearing to perceive, to understand the music, by listening to understand, to love music, by hearing to experience, to distinguish music, by hearing to tell the melody, rhythm, beat characteristics And the use of, by hearing to understand the theme of music development and creative style, by listening to understand the spirit of music, music, philosophy, music, joy, anger, sadness, music, worry, thinking, injury mood. If there is no music to hear, then it is to leave the feelings and feelings of the works on paper.

\section{Tips For Improving Piano Accompaniment}

Piano accompaniment is perfect, with the piano skills and understanding of the music are closely linked. Players want to have a perfect recital, so that the piano accompaniment to achieve the best results must be fully aware of the characteristics of each note, and in the process of perception, the quality of each syllable for a comprehensive analysis, This not only improves the quality of each note playing, but also enhances the player's perceived ability. Players can practice piano accompaniment through daily music auditory exercises to improve the artistic performance of the piano accompaniment and play an important role in the success of the concert. In the process of piano accompaniment, notes are an important part of a series of notes. Therefore, in the process of piano accompaniment, the player to each note playing skills, finger touch the intensity of the full control, so as to achieve the best piano accompaniment, so that the charm of the piano to fully show The As a result, the player makes an important contribution to the success of the concert by using music audition to improve his playing skills. 


\section{Conclusion}

Music listening plays an important role in piano accompaniment. In this paper, the role of music in the piano accompaniment in a brief analysis and elaboration, the player in the piano accompaniment process, the music can play a certain guiding role, so that the player in the piano accompaniment to understand their own shortcomings and shortcomings , Which can not only play a supervisory role, but also for the enjoyment of a perfect music feast, showing the piano accompaniment aesthetic value and artistic value.

\section{References}

[1] Shen Shuwen. On the importance of the establishment of auditory music in piano [J]. Journal of Tianjin Conservatory of Music. 2006 (03)

[2] Jiang Li. On the importance of auditory training in piano teaching [J]. Art 100. 2006 (05)

[3] Xu Yao. The importance of hearing in piano learning [J]. Art Education. 2006 (09)

[4] Lin Fengqing. The inner music music in the music performance of the hierarchical status and its establishment [J]. Art Exploration. 2005 (S2)

[5] Wang Lina. Music listening in the piano learning role [J]. Art Education. 2005 (05)

[6] Zhong Qing. On the importance of auditory perception in music education [J]. Chinese Music Education. 2005 (07) 